\title{
Ilex paraguariensisA. St.-Hil. (Yerba Mate) Differently Regulates the Lipid Mobilization and Irisin and Lactate Levels in Sedentary and Chronic Swimming Mice
}

\author{
V. L. de Souza, E. T. G. Stutz, M. E. de S. F. Pehrson, G. C. Coelho, \\ C. C. Netto, and C. A. B. de Maria
}

\section{ABSTRACT}

Healthy mice were submitted or not to daily chronic swimming and/or daily yerba mate (YM) infusion intake and had their bloods analyzed after four weeks. We hypothesized that daily intake of YM may act differently on lipid mobilization and, on the creatine, lactate and irisin levels in sedentary mice and those submitted to chronic exercise. The groups were $(n=48)$ : YM-non-treated control (NTC), YM-non-treated swimming control (NSC), non-roasted YM (NRY), roasted YM (RY), swimming plus non-roasted YM (SNRY), swimming plus roasted YM (SRY). No significant $(\mathrm{P}>0.05)$ difference was observed concerning creatine phosphoskinase (CPK) value. Lactate level decreased significantly $(P<0.05)$ for SNRY and SRY, suggesting accelerated lipid mobilization and glycogen sparing potential. There was significant $(\mathrm{P}<0.05)$ body weight loss in all, except for NTC. Higher weight loss in NRY, RY, SNRY and SRY indicated greater lipid mobilization. Thiobarbituric acid reactive substances (TBARS) and irisin had significantly $(P<0.05)$ higher values for $R Y$. This is first report that deals with the effect of YM consumption on serum irisin level. Major amounts of caffeic acid derivatives, slightly increased caffeine and less amount of rutin may be responsible by accelerated lipoperoxidation in sedentary healthy mices chronically treated with roasted YM. Chronically consumed YM plus swimming aid in healthy weight loss. Sedentary lifestyle plus roasted YM chronic consumption may cause accelerated lipid mobilization and increased TBARS production via irisin overexpression leading to an increase in lipoperoxidation.

Keywords: Body weight, irisin, lactate, swimming mice, TBARS, Ylexparaguariensis.

\section{INTRODUCTION}

The YM, a native South American plant, is consumed as a hot or cold beverage which is appreciated around the world. As a valuable dietary source of phytochemicals, such as methylxanthines, phenolic acids, flavonoids, tannins, and ursolic acid-derived saponins [1], YM has potential beneficial health effects in addition to its peculiar taste. Experimental studies targeting the effects of YM on the lipid and carbohydrate metabolism of adipose and musculoskeletal tissues have been steadily increasing for over a decade [2], [3]. A systematic review indicated positive effects on decreasing of both waist circumference and body weight, suggesting an anti-obesity potential [4]. A study carried out with sedentary healthy volunteers did not identify any influence on blood total CPK [5]. In patients with traumatic
Submitted: September 30, 2021

Published: November 17, 2021

ISSN: 2593-8339

DOI: 10.24018/ejmed.2021.3.6.1088

\section{L. de Souza*}

Barra Mansa University Center, Brazil.

(e-mail: vladilopes@gmail.com)

E. T. G. Stutz

Barra Mansa University Center, Brazil.

(e-mail: evandro.tgs@gmail.com) M. E. de S. F. Pehrson

Barra Mansa University Center, Brazil.

(e-mail: moyses.pehrson@ubm.br) G. C. Coelho

Federal University of Fronteira Sul (UFFS), Brazil.

(e-mail: cenicoelho@gmail.com)

C. C. Netto

Biomedical Institute - UNIRIO, Brazil.

(e-mail: claudia.c.netto@unirio.br)

C. A. B. de Maria

Biomedical Institute - UNIRIO, Brazil.

(e-mail: carreb@uol.com.br)

*Corresponding Author brain injury on the other hand there was a positive correlation between YM consumption and lower blood total CPK levels [6].

Effects of YM on energetic metabolism using different exercise intensities have been investigated. The beverage both enhanced fatty acid oxidation and decreased carbohydrate oxidation over a range of exercises intensities, especially in light and moderate exercises [7], [8]. No difference was observed for blood total CPK, lactate and malondialdehyde between different steps of exercise [8]. Reference [9] investigated the effects of YM consumption on muscle damage and strength recovery after acute eccentric bout. Both variables were favourably modulated in the treated group when compared to control. The activity of blood total $\mathrm{CPK}$ on the other hand presented similar behavior in both groups. 
Unfortunately, there is a paucity of experimental studies comparing the effect of YM on sedentary and aerobic exercise conditions in healthy organisms. Further, simultaneous analysis of biochemical parameters and irisin hormone has not been yet reported. Irisin is a miokine that drives the salutary effects of exercise as well lipid mobilization, brown-fat-like development and thermogenesis [10], [11]. Give the scarce studies, our group then hypothesized that the daily intake of YM may exert a different action in the lipid mobilization and, irisin, lactate and creatine levels in sedentary group compared to that submitted to chronic swimming. Thus, our group have investigated the effect of YM on blood total CPK, lactate, body weight, TBARS value and irisin in sedentary and aerobically exercise-trained healthy mice.

\section{MATERIALS AND METHODS}

\section{A. Chemicals}

The 2-thiobarbituric acid was supplied by Merck (Darmstadt, Germany). Phosphoric acid was from "Dinâmica" (São Paulo, Brazil). CPK was from "EBRAM ProdutosLaboratoriaisLtda" (São Paulo, Brazil). All other reagents and solvents were of analytical grade and were purchased from Sigma-Aldrich Chemical Co. (St. Louis, MO, USA).

\section{B. Plant Material Selection and Preparation}

The YM leaves were obtained by Claudio Kovaleski and Silvio Kovaleski producers from the "Ervateira Chiru". It is located in Chapecó, Santa Catarina, SC, Southern Brazil (geographic position $27^{\circ} 090^{\prime} 0500^{\prime \prime}$ south, 52 $380^{\prime} 1400^{\prime \prime}$ west) in November and Dezember 2014. Naturally illuminated fresh leaves were dried in the "Zapeco" stage, packaged in air plastic bags and stored at $-18{ }^{\circ} \mathrm{C}$. Voucher specimen was examined by Dr. Geraldo Ceni Coelho (UFFS, Chapecó, Brazil) and deposited in the "Herbarium Professor Jorge Pedro Pereira Carauta" of the Botanical Department (UNIRIO, Rio de Janeiro, Brazil) under the code HUNI by Dr. Carlos Alberto Bastos de Maria. Dried leaves of YM were roasted at $180{ }^{\circ} \mathrm{C}$ for $10 \mathrm{~min}$ in oven as reported elsewhere [12]. This roasting condition showed the most concentration of caffeic acid conjugates and caffeine and less rutin loss. Roasted dried leaves were stored similarly to dried leaves. Infusions were obtained as follows: Boiling destilled water $(500 \mathrm{~mL})$ was poured over the plant material $(8.571 \mathrm{~g})$, mixed, capped and filtered under gravity after $15 \mathrm{~min}$. The YM infusion concentration was based on previous study with humans [5]. Considering the average weight of $70 \mathrm{Kg}$ of a human being and the average weight of $30 \mathrm{~g}$ of a mouse, a final volume was obtained of $0.2142 \mathrm{~mL}$ to be administered to the mouse. The concentration $\left(17.136 \mathrm{mg} \mathrm{mL}^{-1}\right)$ was adjusted to a volume of $0.1 \mathrm{~mL}$ to reduce the animals' stress during gavage.

\section{Animal Experimental Design}

Forty eight Swiss Webster male mice (Mus musculus) with 35 days old were obtained from the "Barra Mansa" University Center (Barra Mansa, Rio de Janeiro, Brazil) where study was carried out. Animals were housed individually in plastic cages at controlled temperature $\left(21-24{ }^{\circ} \mathrm{C}\right)$ and humidity
(55\%), and with a $12: 12 \mathrm{~h}$ light:dark cycle throughout the study (four weeks). Animals were fed ad libitum with a commercial diet (Labina / Presence, Campinas, São Paulo, Brazil) for all period of study (Table I). Daily feed intake during the experiment was not different between the groups. All animals were classified as having both heterogeneous genetic and conventional sanitary characters. The protocol of this study was approved by Animal Experimental Ethics Committee of the "Barra Mansa" University Center (Barra Mansa, Rio de Janeiro, Brazil) (protocol number: 003/2019).

TABLE I: ANIMAL DIET INGREDIENTS EXPRESSED IN GKG ${ }^{-1}$

\begin{tabular}{cc}
\hline \hline Ingredients & $\mathrm{g} \mathrm{Kg}^{-1}$ \\
\hline \hline Moisture & 130 \\
Crude protein & 230 \\
Ether extract & 45 \\
Carbohydrate & 445 \\
Raw fiber & 50 \\
Mineral matter & 100 \\
Calcium (min.) & 12 \\
Calcium (max.) & 13 \\
Phosphor (min.) & 8.50 \\
Sodium (min.) & 0.27 \\
Lysine (min.) & 12.50 \\
Methionine (min.) & 3.50 \\
\hline \hline
\end{tabular}

min. $=$ minimum

max. $=$ maximum

Commercial diet (Labina / Presence).

Sample size $(\mathrm{n}=48)$ was established according to recommendation from the Animal Experimental Ethics Committee of the "Barra Mansa University Center". Mice were randomly distributed in six groups ( $\mathrm{n}=8$ per group) as follows: YM-non-treated control (NTC), YM-non-treated swimming control (NSC), non-roasted YM (NRY), roasted YM (RY), swimming plus non-roasted YM (SNRY) and swimming plus roasted YM (SRY). The NRY, RY, SNRY and SRY groups were treated with a daily dose of $0.1 \mathrm{~mL} 30$ $\mathrm{g}^{-1}$ mouse weight $\left(17.136 \mathrm{mg} \mathrm{mL}^{-1}\right)$ of $\mathrm{YM}$ in the morning after weighing. The NTC and NSC groups ingested filtered water via gavage in substitution of YM. Animals were weighted weekly in the morning (8:00 am). Swimming protocol was based on previous report [13]. Animals from NSC, SNRY and SRY groups were submitted to progressive adaptive swimming training of three days (first day - $25 \mathrm{~min}$, second day $-30 \mathrm{~min}$ and third day $-45 \mathrm{~min}$ ). After adaptive training, a chronic swimming protocol was carried out as follows: $30 \mathrm{~min}$ for first week, $45 \mathrm{~min}$ for second week and $60 \mathrm{~min}$ for third and forth weeks. Animals were not submitted to chronic swimming protocol in weekend, but they consumed YM during twenty eight days. Glass aquarium at $31{ }^{\circ} \mathrm{C} \pm 1{ }^{\circ} \mathrm{C}$ was used for swimming.

The animals were killed by exsanguinations cardiac punction under anesthesia (Ketamine $100 \mathrm{mg} \mathrm{Kg}^{-1}+$ Xylazine $\left.10 \mathrm{mg} \mathrm{Kg}^{-1}\right)$. The blood samples were centrifuged to obtain serum $\left(1,500 \mathrm{~g} 10 \mathrm{~min}^{-1}\right)$ with a centrifuge "Laborglas" model LGI-DLC-802B (São Paulo, Brazil). Serum samples were stored at $-20{ }^{\circ} \mathrm{C}$ until analysis (30 days maximum after collection).

\section{Biochemical Analysis}

The CPK was analyzed by commercial kit QUIMINAC CKNAC, "CEBRAM ProdutosLaboratoriaisLtda" (São Paulo, Brazil), by means of spectrophotometer model LGI- 
VS-721N (São Paulo, Brazil) set at $340 \mathrm{~nm}$. Analysis of lactate was through of a Biochemical analyser Catalyst One (Company DEXX, São Paulo, Brazil). Lipoperoxidation was analyzed via monitoring of TBARS value based on previous method [14]. The TBARS values were obtained using the malondialdehyde as reference substance. Irisin analysis was carried out in the "LEAC (LaboratórioEspecializadoemAnáliseCientíficas, São Paulo, SP)" laboratory. The kit used was the E-EL-M2743-irisin mouse-lot IBEI5LEH1B supplied by Elabscience (Dallas, TX, USA).

\section{E. Statistical Analyses}

Statistical analysis was initially performed using both Kolmogorov-Smirnov and Shapiro-Wilk normality tests. The variable with normal distribution was submitted to both ANOVA and Newman-Keuls test multiple comparison test. The variable with non-normal distribution was applied ANOVA and Kruskal Wallis test. The level of significance was set at $p<0.05$. All statistical analyses were carried out using GraphPad version 5.0 statistical software package version 5.0 (Los Altos, CA, USA).

\section{RESUlts AND Discussion}

The YM used in the current study had its chemical composition reported by our group elsewhere [12]. Phytochemicals detected in greater amounts were ranked here according to the ascending order as follows: rutin $(0.149 \mathrm{mg}$ $\left.\mathrm{mL}^{-1}\right), 3,4-+3,5$-dicaffeoylquinic acids $\left(0.178 \mathrm{mg} \mathrm{mL}^{-1}\right)$, caffeine $\left(0.183 \mathrm{mg} \mathrm{mL}^{-1}\right)$, syringic acid $\left(0.577 \mathrm{mg} \mathrm{mL}^{-1}\right), 4,5-$ dicaffeoylquinic acid $\left(0.650 \mathrm{mg} \mathrm{mL}^{-1}\right)$, ferulic acid $(0.832 \mathrm{mg}$ $\left.\mathrm{mL}^{-1}\right)$, chlorogenic acid $\left(0.896 \mathrm{mg} \mathrm{mL}^{-1}\right)$, and caffeic acid $\left(0.957 \mathrm{mg} \mathrm{mL}^{-1}\right)$. Presence of larger quantities of cinnamic acid derivatives and caffeic acid conjugates, and minor amounts of caffeine and rutin make YM has a unique composition of bioactive molecules and be a good candidate for modulating the metabolism of adipose and musculoskeletal tissues.

Blood total CPK level for each mice group is shown in Fig. 1. There were not statistical $(p>0.05)$ differences between all the groups. The use of YM alone or combined with aerobic chronic exercise did not accelerate muscle protein catabolism in the experimental model applied. These results agreed with those from the other studies which observed similar pattern in sedentary healthy subjects [5] and in acute light/moderate exercise healthy groups [8]. On the other hand, CPK activity was increased $72 \mathrm{~h}$ after acute eccentric bout in both nontreated and YM-treated groups [9]. Since CPK level was elevated with or without YM consumption, eccentric exercise alone could be responsible for this rise. In fact, eccentrically biased exercise has caused proteolysis in skeletal muscle and the rise in blood CPK [15], [16]. The type of exercise, the time it is performed and the number of repetitions can influence directly blood total CPK levels.

Nowadays, lactate is a substantial energetic source for exercising muscles and fills in at least three roles: larger energy source, major gluconeogenic precursor, and as a signaling molecule [17]. Blood lactate profile in both YMtreated and non-treated groups is illustrated in Fig. 2. Lactate values presented no significantly $(\mathrm{p}>0.05)$ differences between NTC, NSC, NRY and RY groups. There was a synergistic effect between aerobic chronic exercise and YM consumption, which resulted in significantly $(p<0.05)$ lower values for SNRY and SRY groups when compared to other groups. These findings may indicate an accelerated lipid mobilization in SNRY and SRY groups, suggesting occurrence of a glycogen sparing potential. Conversely, there were not differences in the lactate level in distinct steps of acute aerobic exercise [8]. Combination of prolonged exercise and YM intake on the other hand increased and decreased oxidation of lipids and carbohydrates, respectively, when compared to placebo during exercise [7], [18]. Based on the data, our group suggest that the effects of both aerobic chronic exercise and chronic consumption of YM on lactate kinetics parameters may induce greater capacity to clearance blood lactate level.

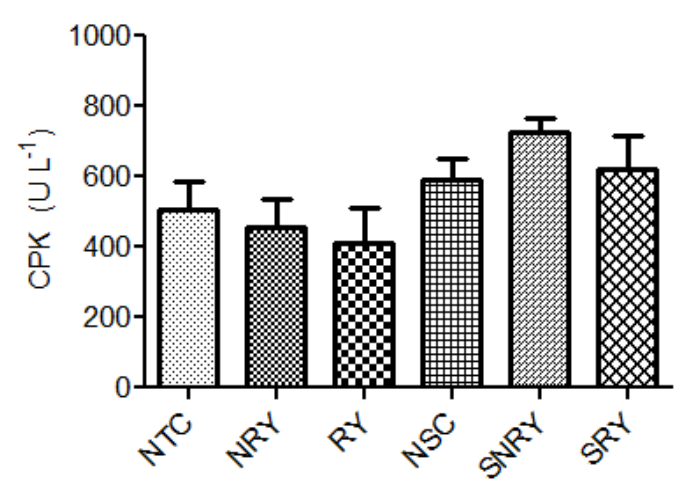

Fig. 1. Blood total creatine phosphokinase (CPK) level in both YM-treated and non-treated groups.

Abbreviations: YM: yerba mate; NTC: YM-non-treated control; NSC: YMnon-treated swimming control; NRY: non-roasted YM; RY: roasted YM, SNRY: swimming plus non-roasted YM; SRY: swimming plus roasted YM. No letters indicate no significant differences $(\mathrm{P}>0.05)$ between the groups. These values showed non-normal distribution to Kolmogorov-Smirnov and Shapiro-Wilk normality tests. ANOVA and Kruskal Wallis tests were applied.

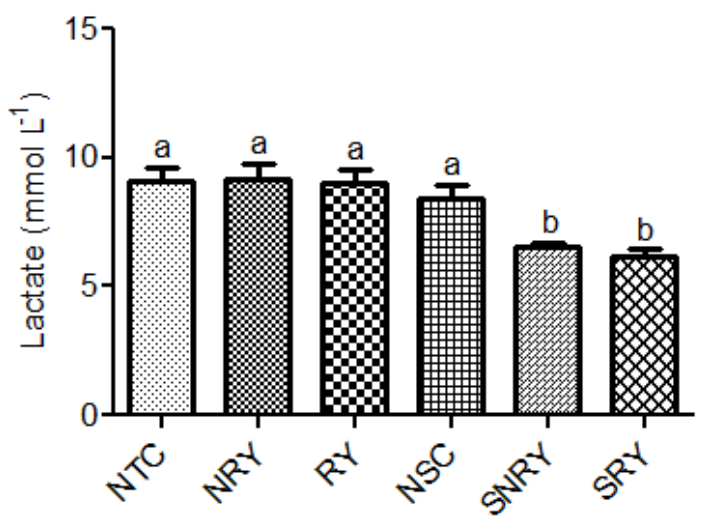

Fig. 2. Blood lactate profile in both YM-treated and non-treated groups. Abbreviations: NTC: YM: yerba mate; YM-non-treated control; NSC: YMnon-treated swimming control; NRY: non-roasted YM; RY: roasted YM, SNRY: swimming plus non-roasted YM; SRY: swimming plus roasted YM. Different letters indicate significant differences $(\mathrm{P}<0.05)$ between the groups. These values showed normal distribution to Kolmogorov-Smirnov and Shapiro-Wilk normality tests. ANOVA and Newman-Keuls tests were applied.

Fig. 3 shows the body weight loss for each mice group. Significant $(\mathrm{p}<0.05)$ losses were observed, especially in the last week, in the NRY, RY, SNRY and SRY groups. There 
was slightly higher body weight loss in the training associated with YM intake compared to training alone. The positive effect of the chronic consumption of YM was probably through increase in both accelerated lipid mobilization and thermogenesis. Anti-obesity, lipid oxidation and thermogenesis effects of YM have been well documented in recent studies [3], [4], [7], [8], [18], [19]. Surprisingly, the most body weight loss was found in the YM-treated sedentary groups, indicating greater lipid mobilization and thermogenesis potential than that from training plus YM consumption. Accelerated lipid mobilization without increased energy expenditure in sedentary mice groups chronically treated with YM may both reduce the efficiency of fatty acids oxidative degradation and induce a greater production of reactive oxygen species (ROS). Accumulation of ROS generates lipoperoxidation-derived reactive carbonyls [20].

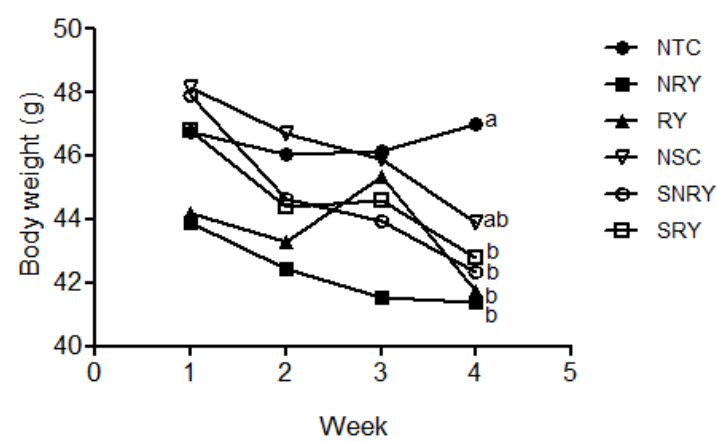

Fig. 3. Body weight (g) weekly in both YM-treated and non-treated groups. Abbreviations: YM: yerba mate; NTC: YM-non-treated control; NSC: YMnon-treated swimming control; NRY: non-roasted YM; RY: roasted YM, SNRY: swimming plus non-roasted YM; SRY: swimming plus roasted YM. No letters indicate no significant differences $(\mathrm{P}>0.05)$ between the groups. Different letters indicate significant differences $(\mathrm{P}<0.05)$ between the groups. The first, second and third weeks body weight mean values showed normal distribution to Kolmogorov-Smirnov and Shapiro-Wilk normality tests. The last week body weight mean values showed non-normal distribution to Kolmogorov-Smirnov and Shapiro-Wilk normality tests. ANOVA and Newman-Keuls tests were applied to first, second and third weeks body weight values; ANOVA and Kruskal Wallis tests were applied to last week body weight values.

Our group then decided to analyze blood TBARS value in non-treated and YM-treated groups. Blood TBARS level is a well-known biomarker to evaluate lipoperoxidation [21]. This parameter had significantly $(\mathrm{p}<0.05)$ higher value for RY group in comparison with other groups (Fig. 4). Differences in the composition of phytochemicals between non-roasted and roasted YM could explain the higher amounts of TBARS in the RY group. In our previous study [12], a relative increase in the contents of caffeine (9\%), chlorogenic acid (18\%), and 4,5-dicaffeoylquinic acid (31 $\%$ ) occurred after roasting at $180^{\circ} \mathrm{C}$ for $10 \mathrm{~min}$. These bioactive molecules had superior thermal stability. Rutin content on the other hand decreased in $35 \%$. Combination of caffeine and chlorogenic acid has induced accelerated lipid oxidation through AMPK-LXR $\alpha /$ SREBP-1c signaling pathway activation [22], [23]. Rutin has been associated with improvement in both mitochondrial machinery and uncoupling protein I (UCP-1) activation via AMPK/SIRTPGC-1 $\alpha$ signaling pathway positive modulation [24], [25]. Larger amounts of caffeic acid derivatives, slightly increased caffeine and less amount of rutin may be responsible by accelerated lipoperoxidation in sedentary healthy mices chronically treated with roasted YM.

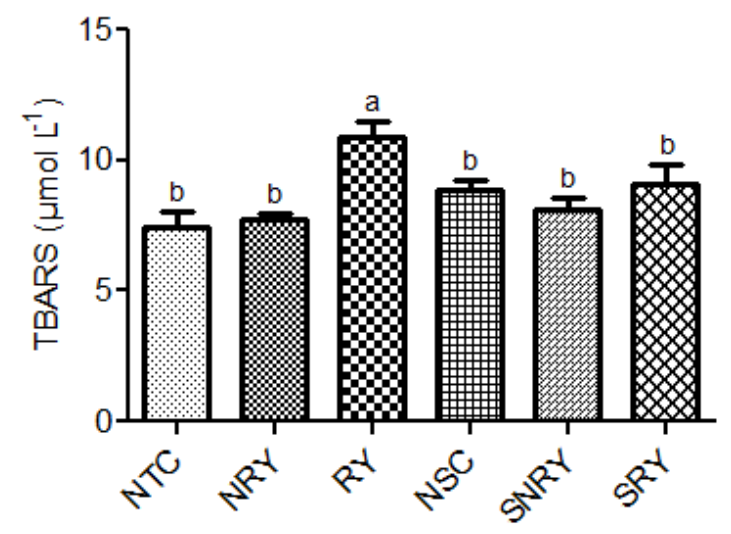

Fig. 4. Blood thiobarbituric acid reactive substances (TBARS) value in non-treated and YM-treated groups.

Abbreviations: YM: yerba mate; NTC: YM-non-treated control; NSC: YMnon-treated swimming control; NRY: non-roasted YM; RY: roasted YM, SNRY: swimming plus non-roasted YM; SRY: swimming plus roasted YM. Different letters indicate significant differences $(\mathrm{P}<0.05)$ between the groups. These values showed normal distribution to Kolmogorov-Smirnov and Shapiro-Wilk normality tests. ANOVA and Newman-Keuls tests were applied.

Since irisin modulates the energy metabolism of musculoskeletal and adipose tissues, which can alter the energy balance, our group decided to investigate the irisin profile. Irisin induces lipid mobilization, browning and thermogenesis via UCP-1 activation and mediates beneficial effects of exercise on metabolism [11]. The mean value of blood irisin in non-treated and YM-treated mice groups is shown in Fig. 5. To our knowledge, this is first report of the YM effect on irisin hormone level. A significant $(\mathrm{p}<0.05)$ higher value was found in RY group in comparison with NTC, NSC, SNRY and SRY groups. This pattern was similar to that found in TBARS analysis (Fig. 4). The blood of RY group was submitted to irisin assay while that of NRY group did not, because the first one had significantly $(p<0.05)$ higher values for TBARS. Accelerated lipid mobilization without counterpart of increase energy expenditure may promote energy imbalance resulting in increased susceptibility to lipoperoxidation. Aerobically exercisetrained healthy mices chronically treated with YM had a better energy balance because the blood irisin level could stabilize at a lower level with chronic aerobic training. Indeed, no enhancement effect of chronic training on circulating irisin levels has been observed [26], [27]. New insights have focused on epigenetic regulation of irisin hormone secretion by PGC-1 $\alpha$ overexpression in musculoskeletal and adipose tissues [28]. Combination of aerobic chronic exercise and chronic intake of YM may activate thermogenesis and ameliorate mitochondrial function via AMPK/SIRT-PGC-1 $\alpha$-irisin-UCP-1. This hypothesis needs further investigation.

In conclusion, our group found that YM acted differently in the sedentary group in comparison with the group submitted to swimming. Aerobic chronic exercise associated with chronically consumed YM is a safe strategy to aid healthy body weight loss. Chronic consumption of roasted YM associated with a sedentary lifestyle should be viewed 
with caution as it may cause accelerated lipid mobilization and an excessive TBARS production via irisin overexpression leading to an increase in lipoperoxidation.

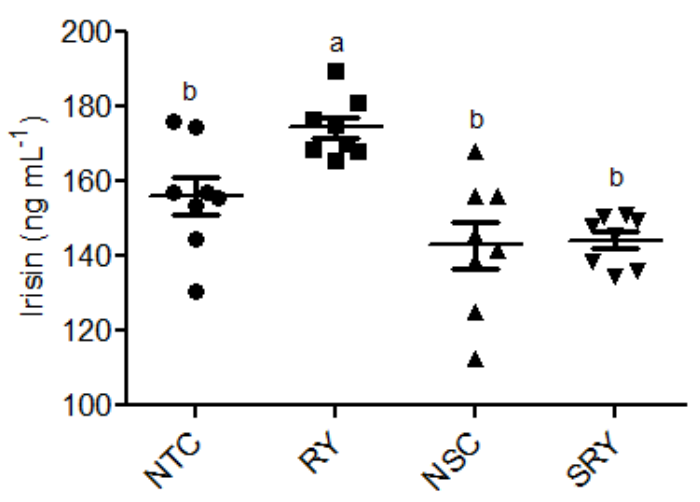

Fig. 5. Blood irisin level in non-treated and YM-treated mice groups. Abbreviations: YM: yerba mate; NTC: YM-non-treated control; NSC: YMnon-treated swimming control; NRY: non-roasted YM; RY: roasted YM, SNRY: swimming plus non-roasted YM; SRY: swimming plus roasted YM. Different letters indicate significant differences $(\mathrm{P}<0.05)$ between the groups. These values showed normal distribution to Kolmogorov-Smirnov and Shapiro-Wilk normality tests. ANOVA and Newman-Keuls tests were applied.

\section{ACKNOWLEDGMENT AND CONFLICT OF INTEREST}

The authors thank the laboratory team from "Barra Mansa" University Center.

\section{FUNDING}

This research did not receive any specific grant from funding agencies in the public, commercial, or not-for-profit sectors.

\section{REFERENCES}

[1] Borré GL., Kaiser S., Pavei C., da Silva FA., Bassani VL., Ortega G. Comparison of methylxanthine, phenolics and saponin contents in leaves, branches and ripe fruits from Ilex paraguaiensis A. St.-Hil. $J$ Liq Chromatog Relat Technol. 2010, 33: 362-374.

[2] Cardozo Junior EL., Morand C. Interest of mate (Ilex paraguariensis A. St.-Hil.) as a new natural functional food to preserve human cardiovascular healthy - A review. J. Funct Foods. 2016; 21: 440-444.

[3] Riachi LG., de Maria CAB. Yerba mate: An overview of physiological effects in humans. J Funct Foods. 2017; 38: 308-320.

[4] Luís AFS., da C. Domingues F., Amaral LMJP. The anti- obesity potential of Ilex paraguaiensis: results from a metaanalysis. Braz J Pharm Sci. 2019; 55: e17615.

[5] Riachi LG., Marcellini PS., de Maria CAB., Coelho GC. Yerba Mate consumption effect on the total concentration of creatine phosphokinase in healthy volunteers from the Age of 50. Eur J Med. Health Sci. 2019; 1: 1-3.

[6] Ribeiro MC., Santos A., Riachi LG., Rodrigues ACB., Coelho GC. Marcellini PS., de Maria CAB. The effects of roasted yerba mate (Ilex paraguariensis A. ST. Hil.) consumption on glycemia and total serum creatine phosphokinase in patients with traumatic brain injury. JFunct Foods, 2017; 28: 240-245.

[7] Alkhatib A. Yerba Maté (Ilex Paraguariensis) ingestion augments fat oxidation and energy expenditure during exercise at various submaximal intensities. Nutr Metab. 2014: 11; 42.

[8] de M. Cazal M. Efeito da ingestão de chá mate (Ilex paraguariensis) antes do exercícioaeróbicosobreindicadoresmetabólicos de dano muscular e estresseoxidativo. Ph.D. Thesis. Federal University of Viçosa, 2019.

[9] Moura BM., Panza VP., Brunetta HS., Tamborindeguy AC., de Oliveira MV., Sakugawaet RF. et al. Effect of mate tea consumption on rapid force production after eccentric exercise: a randomized, controlled, crossover study. Sport Sci Health. 2020;6: 1-11.
[10] Wu J., Boström P., Sparks LM., Ye L., Choi JH., Gianget AH., et al. Beige Adipocytes Are a Distinct Type of Thermogenic Fat Cell in Mouse and Human. Cell. 2012; 150: 366.

[11] Nirajan SB., Belwalkar SV., Krishnan ST., Mookhtiar KA. Recombinant irisin induces weight loss in high fat DIO mice through increase in energy consumption and thermogenesis. Biochem Biophys Res Commun. 2019; 519: 422-429.

[12] Riachi LG., Simas DLR., Coelho GC., Marcellini PS., da Silva AJR., de Maria CAB. Effect of light intensity and processing conditions on bioactive compounds in mate extracted from yerba mate (Ilex paraguariensis A. St.-Hil.). Food Chem. 2018; 266: 317-322.

[13] Lima FD., Stamm DN., Della-Pace ID., Dobrachinski F., de Carvalho NR., Royeset LF., et al. Swimming training induces liver mitochondrial adaptations to oxidative stressin rats submitted to repeated exhaustive swimming bouts. PLoS One. 2013; 8: e55668.

[14] Grotto D., Valentini J., Boeira S., Paniz C., Maria LS., Vicentin J. et al. Avaliação da estabilidade do marcadorplasmático do estresseoxidative. Quim Nova. 2008; 31: 275-279, Portuguese.

[15] Stupka N., Tarnopolsky MA., Yardley NJ., Phillips SM. Cellular adaptation to repeated eccentric exercise-induced muscle damage. $J$ Appl Physiol. 2001; 91: 1669-1678.

[16] Broos S., Malisoux L., Theisen D., Van Thienen R., Francaux M., Thomiset M., et al. The stiffness response of type Ilafibres after eccentric exercise-induced muscle damage is dependent on ACTN3 r577X polymorphism. Eur J Sport Sci. 2019; 19: 480-489.

[17] Brooks GA. Lactate as a fulcrum of metabolism. Redox Biol. 2020; 35.

[18] Alkhatib A., Atcheson R. Yerba Maté (Ilex paraguaiensis) Metabolic, Satiety, and Mood State Effects at Rest and during Prolonged Exercise. Nutrients. 2017; 9: 882.

[19] dos Santos TW., Miranda J., Teixeira L., Aiastui A., Matheu A., Gambero A. Yerba Mate Stimulates Mitochondrial Biogenesis and Thermogenesis in High-Fat-Diet-Induced Obese Mice. Mol Nutr Food Res. 2018: 31; e1800142.

[20] Gaschler MM., Stockwell BR. Lipid Peroxidation in cell death. Biochem Biophys Res Commun. 2017; 482: 419-5.

[21] Ghani AM., Barril C., Jr Bedgood DR., Prenzler PD. Measurement of antioxidant activity with the thiobarbituric acid reactive substances assay. Food Chem. 2017; 230: 195-207.

[22] Xu M., Yang L., Zhu Y., Liao M., Chu L., Li X. Collaborative effects of chlorogenic acid and caffeine on lipid metabolism via the AMPK $\alpha$ LXR $\alpha$ /SREBP-1c pathway in high-fat diet-induced obese mice. Food Funct. 2019; 10: 7489-7497.

[23] Kong L., Xu M., Qiu Y., Liao M., Zhang Q., Yang L., et al. Chlorogenic acid and caffeine combination attenuates adipogenesis by regulating fat metabolism and inhibiting adipocyte differentiation in 3T3-L1 cells. J Food Biochem. 2021; 45: e13795.

[24] Seo S., Lee MS., Chang E., Shin Y., Oh S., Kim IH., Kim Y. Rutin Increases Muscle Mitochondrial Biogenesis with AMPK Activation in High-Fat Diet-Induced Obese Rats. Nutrients. 2015; 7: 8152-8169.

[25] Yuan X., Wei G., You Y., Huang Y., Lee HJ., Donget M., et al.Rutin ameliorates obesity through brown fat activation. FASEB J. 2017; 31: 333-345.

[26] Norheim F., Langleite TM., Hjorth M., Holen T., Kielland A., Stadheimet HK., et al. The effects of acute and chronic exercise on PGC-1 $\alpha$, irisin and browning of subcutaneous adipose tissue in humans. FEBS J. 2014; 281: 739-49.

[27] Qiu S., Cai X., Sun Z., Schumann U., Zügeland M., Steinacker JM. Chronic exercise training and circulating irisin in adults: A Metaanalysis. Sports Med, 2015; 45: 1577-1588.

[28] Cheng C-F., Ku H-CV., Lin H. PGC-1 $\alpha$ as a Pivotal Factor in Lipid and Metabolic Regulation. Int J Mol Sci. 2018; 19: 3447.

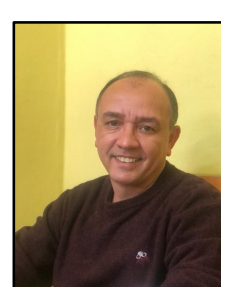

L. de Souza is Graduated in Physiotherapy from the Catholic University of Petrópolis (1999), Specialization in Sports and Cardiovascular Physiotherapy (2001), Specialist in Health Education for SUS Preceptors (2014), Master in Science of Human Motricity from Castelo Branco University (2006) and Doctoral Student in Nursing and Biosciences at the Federal University of Rio de Janeiro (UNIRIO) (2019). Coordinator of the Physiotherapy Course (University Center of Barra Mansa/2011). Coordinator of the Postgraduate Course in Geriatrics and Gerontology (UBM). Member of the Ethics Committee of UBM, Associate Member of the Brazilian Association of Teaching in Physiotherapy (ABENFISIO). 


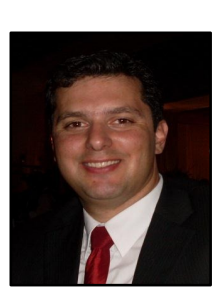

E. T. G. Stutz is Veterinary Doctor Student, Master of Science and specialist in animal morphophysiology, with experience in academic laboratories and vivarium. Personnel training, preparation of training courses, production of manuals (institutional teaching material) and standardization of procedures (POPs) in vivarium. Professor for 40 hours of the Veterinary Medicine Course at Centro Universitário de Barra Mansa UBM, with experience in the disciplines of Bioterism, Cell Biology, Embryology, Histology and Biophysics. Technical Manager for the Animal Breeding and Experimentation Animal Facility at UBM. Veterinary Duty Doctor Professor at the Small Animal Clinic of UBM, providing clinical care and academic internship guidance.

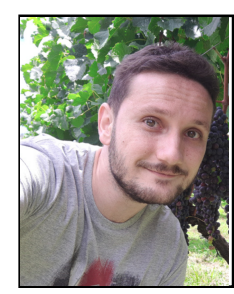

M. E. de S. F. Pehrson is Biologist, Specialist in Biochemistry, Master in Industrial Biotechnology in the area of Applied Microbiology from EELUSP. $\mathrm{PhD}$ in the area of Applied Microbiology by the Industrial Biotechnology program of EEL-USP. Laboratory Supervisor at University Center of Barra Mansa (UBM). Also works in research involving probiotic microorganisms and characterization of fermented products.

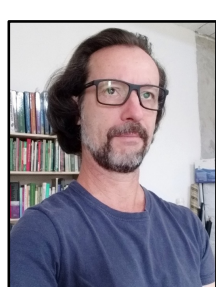

G. C. Coelho is Biologist, Master in Botany (UFRGS - Rio Grande do Sul Federal University, Porto Alegre, Brazil, 1996), Doctor in Pharmaceutical Sciences (UFRGS, 2002), He works on chemical ecology, ecophysiology and forest ecology. Member of the Post-Graduation in Environmental Science and Technology, Fronteira Sul Federal University (UFFS) at Erechim, Brasil.

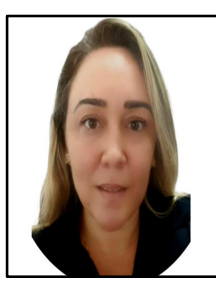

C. C. Netto is Graduated in Nutrition from the Federal University of the State of Rio de Janeiro (UNIRIO), Master's and Doctorate in Food, Nutrition and Metabolism from the State University of Campinas (UNICAMP) and PostDoctorate in Women's Health from the Oswaldo Cruz Foundation (FIOCRUZ) / Fernandes Figueira Institute (IFF).

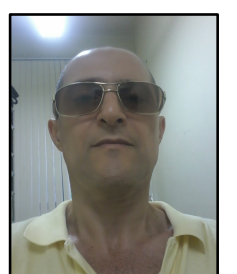

C. A. B. de Maria is Graduated in Nutrition from the Federal University of Rio de Janeiro (1987), Master in Biochemistry from the Federal University of Rio de Janeiro (1991) and Doctor in Biochemistry from the Federal University of Rio de Janeiro (1995). He is currently a professor at the Department of Public Health at the Biomedical Institute of the Federal University of the State of Rio de Janeiro (UNIRIO). Has experience in Food Science and Nutrition, with emphasis on Chemistry, Physics, Physical Chemistry and Biochemistry of Alim. and of Food Raw Materials. 